\title{
MATERIALS CHARACTERIZATION OF ELECTRON BEAM MELTED Ti-6Al-4V
}

\author{
Susan Draper ${ }^{1}$, Brad Lerch ${ }^{1}$, Richard Rogers ${ }^{1}$, Richard Martin ${ }^{2}$, Ivan Locci ${ }^{3}$, Anita Garg ${ }^{3}$ \\ ${ }^{1}$ NASA Glenn Research Center, Cleveland, OH \\ ${ }^{2}$ Cleveland State University, Cleveland, $\mathrm{OH}$ \\ ${ }^{3}$ University of Toledo, Toledo, $\mathrm{OH}$
}

\begin{abstract}
An in-depth material characterization of Electron Beam Melted (EBM) Ti-6Al-4V material has been completed. Hot Isostatic Pressing (HIP) was utilized to close porosity from fabrication and also served as a material heat treatment to obtain the desired microstructure. The changes in the microstructure and chemistry from the powder to pre-HIP and post-HIP material have been analyzed. Computed tomography (CT) scans indicated porosity closure during HIP and high-density inclusions scattered throughout the specimens. The results of tensile and high cycle fatigue (HCF) testing are compared to conventional Ti-6Al-4V. The EBM Ti-6Al-4V had similar or superior mechanical properties compared to conventionally manufactured Ti-6Al-4V.
\end{abstract}

\section{Introduction}

In cooperation with the United States Air Force to advance technologies for inspace propulsion systems, NASA has generated a material database for EBM Ti6Al-4V. While Ti-6Al-4V has been manufactured by electron beam melting for a number of years, a database of microstructure and corresponding mechanical properties from cryogenic to elevated temperatures was needed for component design. A complete database, including low cycle fatigue, fatigue crack growth, fracture toughness and thermal properties has been generated [1]; however, this paper will include only the tensile and
HCF properties. The ultimate goal is to use additive manufacturing to produce a Ti-6Al$4 \mathrm{~V}$ gimbal cone for the RL10 rocket engine. Additive manufacturing enables a reduction in component ordering lead-time and a reduction in cost compared to the currently forged and machined $\mathrm{Al}$ alloy component. Electron beam melting (EBM) was selected as the additive manufacturing technique as it has the advantages of operating in a vacuum to reduce oxygen pick-up and reduced residual stresses.

\section{Material and Test Procedure}

The EBM Ti-6Al-4V material was procured from the Department of Energy's Kansas City Plant at the National Secure Manufacturing Center (NSMC). The specimens were fabricated by an Arcam A2X EBM machine using EBM Control Software Version 3.2.132 and the standard Arcam Ti6Al4V $50 \mu \mathrm{m}$ Theme Version 3.2.121 [2]. The samples were fabricated under eight separate builds with the material divided into two lots for material testing purposes. The samples were fabricated oversized to allow for machining. Specimen cubes and cylindrical bars were fabricated vertically for the majority of the specimens but a small build of horizontal, cylindrical samples was also fabricated to check for orientation effects. Microstuctural features were measured on 5 micrographs per sample and the feature sizes were estimated using line lengths that do not account for threedimensional shape. All error bars represent 95\% confidence intervals. 


\begin{tabular}{|c|c|c|c|c|c|c|c|c|c|}
\hline \multicolumn{10}{|c|}{ Table I. Chemistry (wt \%) } \\
\hline & $\mathrm{Ti}$ & $\mathrm{Al}$ & $\mathrm{V}$ & $\mathrm{C}$ & $\mathrm{O}$ & $\mathrm{N}$ & $\mathrm{Fe}$ & $\mathrm{Cr}$ & $\mathrm{Si}$ \\
\hline Powder & Bal. & 6.57 & 3.98 & 0.008 & 0.23 & 0.022 & 0.13 & 0.008 & 0.01 \\
\hline As Fab. & Bal. & 6.01 & 3.87 & 0.009 & 0.23 & 0.023 & 0.12 & 0.007 & 0.009 \\
\hline Post HIP, Lot 1 & Bal. & 6.26 & 3.93 & 0.009 & 0.23 & 0.021 & 0.11 & 0.007 & 0.011 \\
\hline Post HIP, Lot 2 & Bal. & 5.92 & 3.89 & & 0.25 & 0.022 & 0.10 & 0.006 & 0.009 \\
\hline Post HIP, Hor. & Bal. & 6.2 & 3.97 & & 0.26 & 0.023 & 0.14 & 0.007 & 0.013 \\
\hline ASTM F2924 & Bal. & $5.5-$ & $3.5-$ & Max. & Max. & Max. & Max. & Max. & Max. \\
& & 6.75 & 4.5 & 0.08 & 0.2 & 0.05 & 0.30 & 0.1 & 0.1 \\
\hline
\end{tabular}

All mechanical test samples were hot isostatically pressed (HIP) to close internal porosity at $899^{\circ} \mathrm{C} / 103 \mathrm{MPa}$ for 2 hours. Tensile tests were performed in strain control at a rate of $.0001 / \mathrm{sec}$. HCF tests were conducted in load control at a frequency of 20-30 Hz. Tests were performed using a sinusoidal waveform at three load ratios, $\mathrm{R}_{\sigma}$, of $-1,0.1$, and 0.5 and test temperatures of $-196,20$, and $149^{\circ} \mathrm{C}$. Ten million cycles was the runout value for the long-term tests. The crack origin(s) on every sample was identified using optical microscopy and SEM.

\section{Results and Discussion}

The chemistry of the starting powder, taken from the Arcam machine after every build, and fabricated samples were analyzed, Table I. The powder composition was uniform from build to build so only one composition is given in Table I. The oxygen content of the starting powder was above the ASTM standard limit and remained there after fabrication and HIP. All other elements were within the specification range.

In the as-manufactured state, the sample contained a population of porosity that was detected by computed tomography (CT) and metallography. Pore size was measured on a metallographic sample and averaged $33 \pm 4 \mu \mathrm{m}$, with pore size ranging from 7 to $106 \mu \mathrm{m}$. Following HIP, CT and metallography confirmed full porosity closure. High-density indications were observed in the CT scans and these remained after HIP.

The hot isostatic pressure (HIP) temperature was below the $\beta$ transus temperature for Ti-6Al-4V. The post HIP microstructure is made up of columnar prior $\beta$ grains, a transformed $\alpha+\beta$ microstructure, Figure 1. The columnar microstructure is best observed in optical micrographs of longitudinal samples etched with Kroll's, Figure 2. The EBM processing theme utilized $50 \mu \mathrm{m}$ thick layers and the build layers are not visible in the microstructure. The prior $\beta$ grains extend beyond several build layers. Transmission electron microscopy confirmed the presence of $\alpha$ and $\beta$ phases.

The microstructural features important to mechanical properties are prior beta grain size, colony size and lath thickness and these are given in Table II. There were no primary alpha grains present in the EBM microstructure. The prior beta grains extended in the $\mathrm{z}$ or build direction but were not defined enough to enable a measurement so only the $\beta$ grain size in the transverse direction is given. A typical Ti6Al-4V lamellar microstructure has uniform colonies with all the $\alpha / \beta$ laths going in the same direction. The EBM microstructure had the orientation of the laths changing frequently, often within a few laths. The 
Table II. Microstructure Characterization

\begin{tabular}{|c|c|c|c|}
\hline Sample & $\begin{array}{c}\text { Colony } \\
\text { size, } \mu \mathrm{m}\end{array}$ & $\begin{array}{c}\alpha \text { lath } \\
\text { thicknes } \\
\mathrm{s}, \mu \mathrm{m}\end{array}$ & $\begin{array}{c}\beta \\
\text { Grain } \\
\text { Size, } \\
\mu \mathrm{m}\end{array}$ \\
\hline Lot 1 & $7.7 \pm 0.5$ & $1.9 \pm 0.1$ & $82 \pm 9$ \\
\hline Lot 2 & $6.8 \pm 0.4$ & $1.9 \pm 0.1$ & $82 \pm 9$ \\
\hline Horiz. & $11.1 \pm 0.7$ & $2.8 \pm 0.2$ & \\
\hline
\end{tabular}

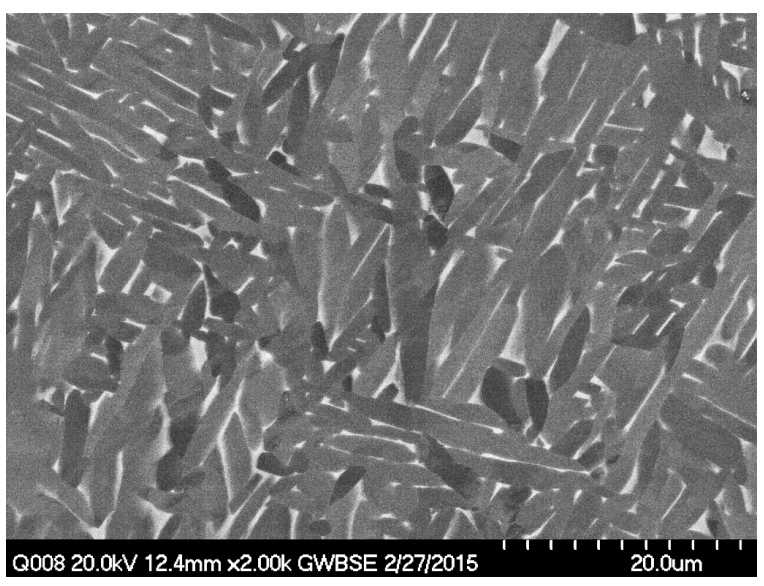

Figure 1. Backscattered electron image of EBM Ti-6Al-4V with the direction transverse to growth direction.

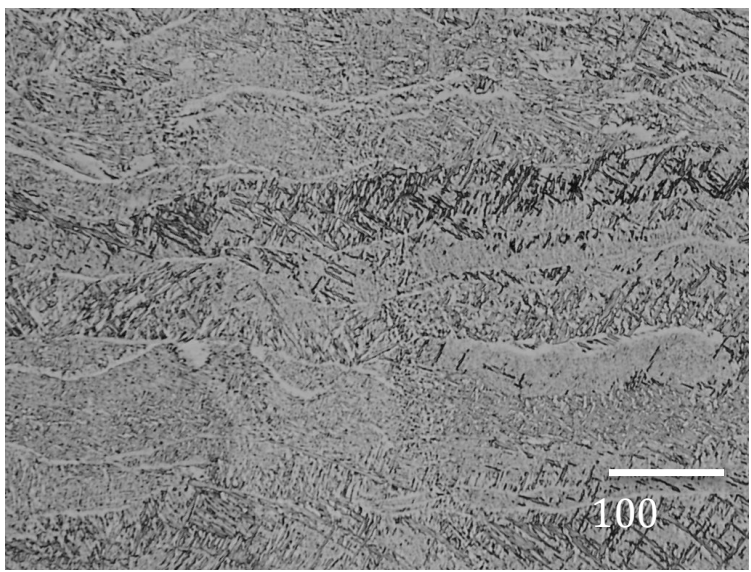

Figure 2. Optical image of EBM Ti-6Al$4 \mathrm{~V}$ in longitudinal direction showing $\alpha$ phase at prior $\beta$ grain boundaries.

colony size and alpha lath thicknesses were not significantly different for lot 1 and 2 samples but the horizontal samples had a significantly larger colony size and $\alpha$ lath thickness.

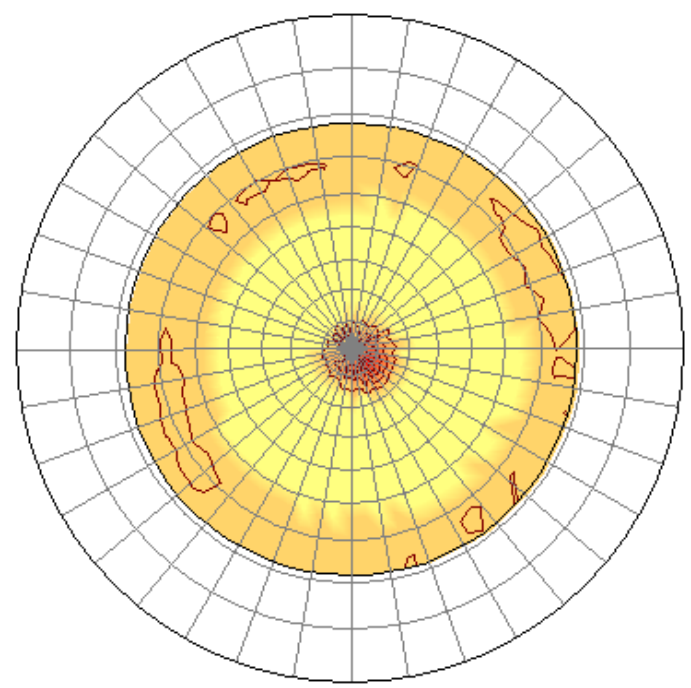

Figure 3. (002) Pole figure from a lot 1 sample showing fiber texture. The build direction was normal to the plane of the pole figure.

X-ray diffraction was used to determine the presence of texture. Lot 1 samples had a fiber texture with hexagonal base planes of the $\alpha$ phase orientated perpendicular to the growth direction, Figure 3. Lot 2 samples had no preferred orientation and the horizontal samples had coexisting (100), (002), and (101) $\alpha$ - fiber texture with all 3 fiber axes parallel to the build direction.

Representative tensile curves from lot 1 and 2 samples at each temperature as well as a horizontal sample are shown in Figure 4. The strength of the material decreases and the ductility increases with increasing temperature. The elastic modulus, $0.2 \%$ offset yield strength (YS) and ultimate tensile strength (UTS) were higher for lot 1 than lot 2 samples with the difference being consistent over the entire temperature range. The horizontal samples had similar strength to lot 2 samples at room temperature (RT) but had lower ductility, averaging $13.4 \%$ failure strain. MMPDS-07 cites S-basis values for annealed extrusions as having an UTS of $896 \mathrm{MPa}$ and failure strains of 10 percent. All of the AM samples exceeded 
these values with the exception of the failure strain for one sample that failed at a lowdensity inclusion containing $\mathrm{Si}, \mathrm{Al}, \mathrm{O}$, and Ca.

The high strength of the EBM material is likely due to it's refined lamellar microstructure with colony sizes on the order of $10 \mu \mathrm{m}$ compared to 20 to $500 \mu \mathrm{m}$ [3, $4,6]$ for conventionally manufactured lamellar microstructures. The difference in strength between lots 1 and 2 can only be explained by the difference in texture. (002) fiber texture has been shown to increase the strength of Ti-6Al-4V [5]. The samples were fabricated within days of each other using the same build parameters; however, the builds were sectioned slightly differently. Lot 1 samples were built in quadrants and halves, with arrays of $4 \times 5$ samples fabricated per quadrant/half, whereas lot 2 was fabricated in sections with arrays of $3 \mathrm{x}$ 3 samples in each section. Lot 1 thus had a longer scan length per section compared to Lot 2. Arcam has studied the effect of array size on tensile strength and found no difference in tensile strength between samples built in a $3 \times 3$ compared to a $5 \times 5$ array [2]. It's not clear why lot 1 had a fiber texture and lot 2 had a random texture. The difference in strength for the horizontal samples could be explained by the larger colony size and alpha lath thickness. Slip length is effectively controlled by the colony size $[3,6]$. Larger colonies allow for longer slip and slightly lower strengths. Additionally, the alpha phase present at the prior beta grain boundaries was perpendicular to the tensile axis. The alpha phase exhibited a brittle appearance on the fracture surfaces of the horizontal samples and is likely the cause of the lower ductility.

A summary of $20^{\circ} \mathrm{C}$ high cycle fatigue results is given in Figure 5. Noted on this figure are samples that failed from $\mathrm{Nb}$ inclusions, Figure 6. These inclusions were detected with NDE and noted as highdensity inclusions scattered throughout all the samples. The inclusions appear to be round powder particles and contain only $\mathrm{Nb}$. The Arcam system utilized was a dedicated Ti-6Al-4V system and no other alloy has ever been melted in this system. It is believed the $\mathrm{Nb}$ came from the starting powder.

HCF data on conventionally manufactured, annealed Ti-6-4 samples tested at NASA for an ASTM E466 round robin exercise is plotted in Figure 5 along with three curves, which were taken from MMPDS-07 for annealed Ti-6-4 at three equivalent mean stresses $(0,324$, and 483 $\mathrm{MPa})$. These mean stresses are similar to those used for the additive manufactured testing ${ }^{1}$. The UTS for this material was 945 $\mathrm{MPa}$ and is $100 \mathrm{MPa}$ lower than the lowest ultimate strength value exhibited by the AM material. The lines in Figure 5 were reconstructed from the best-fit equations based on equivalent stresses in the MMPDS chapter on Ti-6-4. It is shown that the additive manufactured samples are superior to both the ASTM and MMPDS data. The exception is for the one AM sample, which failed at a surface connected, $\mathrm{Nb}$-inclusion, and even that sample is well within the scatter from the MMPDS data.

Data for the three load ratios $\left(R_{\sigma}=-1\right.$, 0.1 , and 0.5 ) are plotted with specific colors; black for $\mathrm{R}=-1$, orange for 0.1 , and green for .5. At $R=-1$, the fatigue limit of the $A M$ material is $550 \mathrm{MPa}$, significantly higher than the fatigue limit of approximately 350 MPa for MMPDS data. This trend is understandable since the UTS for the lot 1 material is $1130 \mathrm{MPa}$ and for the MMPDS is only $945 \mathrm{MPa}$, a $185 \mathrm{MPa}$ difference. The fatigue limit for the ASTM data is difficult

\footnotetext{
1 The tests from MMPDS were conducted using a constant mean stress, not a constant load ratio as was done with both the AM and ASTM E466 samples.
} 


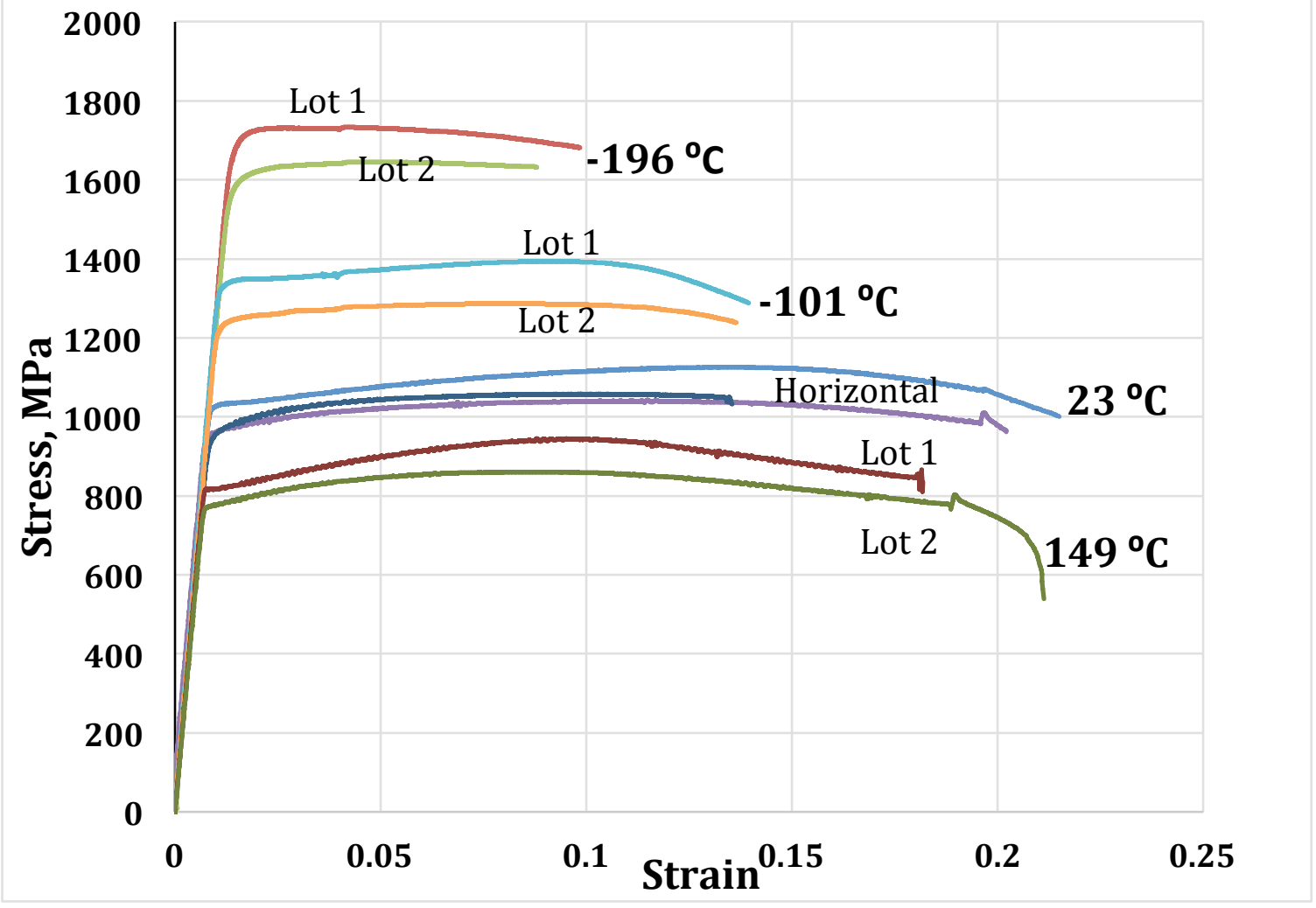

Figure 4. Representative tensile curves for lot 1 and 2 samples at each temperature. A RT horizontal sample curve is shown between the lot 1 and 2 RT curves.

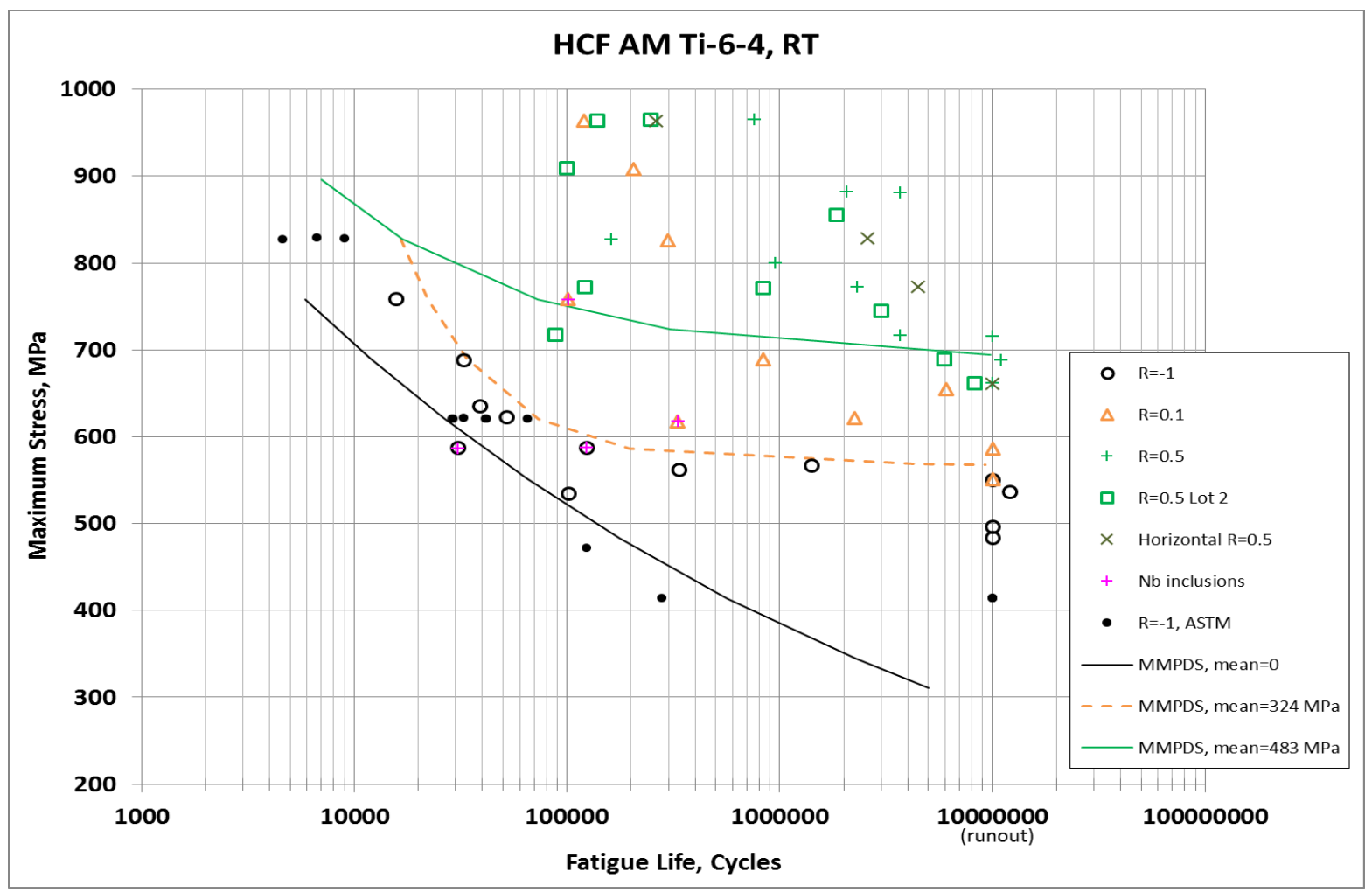

Figure 5. Room temperature HCF data at $R=-1,0.1$, and 0.5 . 


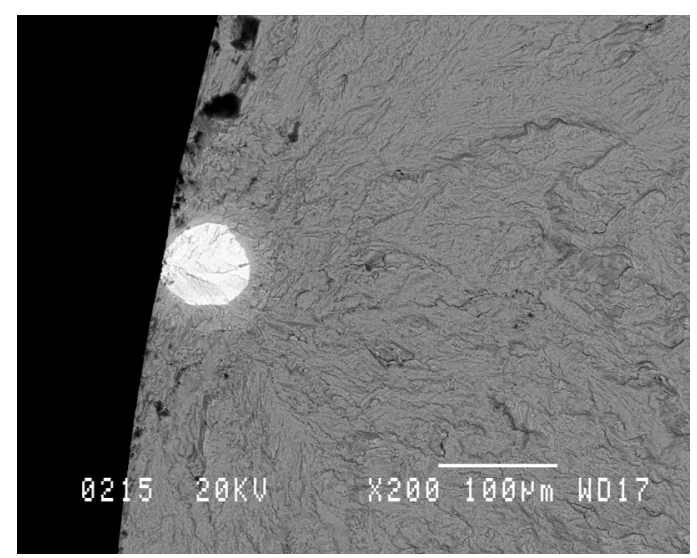

Figure 6. BSE image showing $\mathrm{Nb}$ inclusion at a HCF initiation site.

estimate due to the limited data in the high life regime but a crude estimate would place it at $400 \mathrm{MPa}$. At $\mathrm{R}=0.1$ the $\mathrm{AM}$ data lie completely above the fit line from the MMPDS data. The fatigue limits from both are similar, but the AM has much longer lives at all other stress values for the same maximum stresses. Even the two samples that failed prematurely from surface connected, $\mathrm{Nb}$-inclusions had longer lives than those taken from MMPDS. Finally, at a load ratio of 0.5 the AM samples showed equivalent or better lives than the MMPDS fit, especially at higher stresses. The fatigue limits for the AM samples are similar to those from MMPDS or perhaps even a bit (6 percent) lower for the limits from lot 2 and the horizontal build. However, the data are sparse in this regime. At the higher stress levels $(>700 \mathrm{MPa})$ the data from $\mathrm{R}=0.1$ and 0.5 are very similar indicating that the maximum stress rather than the stress range or mean stress drives the fatigue life. HCF results from cryogenic and elevated temperature are given in the projects final report [1].

\section{Summary and Conclusion}

An in-depth characterization of
Electron Beam Melted (EBM) Ti-6Al-4V material has been completed. The mechanical properties of HIP'ed EBM Ti$6 \mathrm{Al}-4 \mathrm{~V}$ were equivalent or superior to conventionally manufactured material. The high strength of the AM Ti-6Al-4V is attributed to the refined, lamellar microstructure. A significant difference in tensile was observed between the two lots of samples and was attributed to the crystallographic orientation with lot 1 having a strong fiber texture and lot 2 having a random texture. Inclusions, both low and high density, were present in the EBM Ti-6Al-4V but generally did not affect the mechanical properties of the alloy. The excellent mechanical properties of HIP'ed EBM Ti-6Al-4V are sufficient to design and manufacture a quality gimbal or other aerospace components.

\section{References}

1. Draper, S.L. et al: NASA TM to be published in 2015.

2. Svensson, M.: Arcam report MSV083, Arcam AB, 2012.

3. Nalla, R. K.; Boyce, B. L.; Campbell, J.P.; Peters, J.O.; and Ritchie, R.O.: Metall. and Mat. Trans. A, 2002, vol. 33A, pp. 899-918.

4. Tiley, J.; Searles, T.; Lee, E.; Kar, S.; Banerjee, R.; Russ, J.C.; Fraser, H.L.: Mat. Science and Eng. A, 2004, vol. 372, pp. 191-198.

5. Semiatin, S.L. and Bieler, T. R.: Metall. and Mat. Trans. A, 2001, vol. 32A, p.p. 1787-1799, 2001.

6. Lutjering, F. and Albrecht, J.; Titanium '95: Science and Technology Proceedings of the Eighth World Conference on Titanium, ed. Blenkinsop, P.A. et al, 1995, pp. 1163-1170. 